\title{
Tenant mix in shopping centres: South Africa and the United Kingdom compared
}

\author{
A. N. Kyriazis \\ C.E. Cloete \\ Department of Construction Economics \\ University of Pretoria, South Africa
}

\section{Keywords}

Tenant mix, property asset managers, tenant location, tenant mix policies, monitor tenant mix.

\begin{abstract}
The management of tenant mix by shopping centre managers in South Africa was compared with that found to have been used by shopping centre managers in the UK (Downie et al., 2002). Relevant aspects included how to maintain an effective mix, the factors influencing the location of tenants, the extent that tenant mix policies are documented by property asset managers and the monitoring of tenant mix. A total of twenty responses were received from leasing executives (letting agents), retail asset managers, investors, centre managers and property managers in South Africa, representing shopping centers totaling more than 1, 25 million square meters GLA.

The study found that similar levels of importance were given to each aspect by respondents in both the countries. In both studies, anchor tenants were seen to be the most important factor of determining tenant mix and the image of a shopping centre. In the UK retail store specialists played a more dominant role than in South Africa in influencing the shopping centre tenant mix decision and the location of stores within the shopping centre. The lack of required unit sizes and vacant units was found to be the greatest hindrance to the updating of the tenant mix in both studies. A formal tenant mix policy updated on a frequent basis was found to be a determining factor in the keeping the tenant mix relevant and reflecting modern retail trends. The monitoring of turnover by evaluating monthly turnover figures or accessing a turnover index on a monthly or yearly basis was seen as the most important tool to monitoring, and thereby managing, the effectiveness of the tenant mix.

The study provides guidelines to owners, asset managers, managers and investors in South African shopping centers on commonly accepted techniques to maintain a satisfactory tenant mix.
\end{abstract}

Corresponding author: C.E. Cloete

Email addresses for corresponding author:Chris.Cloete@up.ac.za

First submission received: 17th June 2017

Revised submission received: 30 th August 2017

Accepted: 28th September 2017

\section{Introduction}

For a shopping centre to maintain its asset value, the landlord needs to monitor and adjust the tenant mix (Downie, Fisher \& Cheryl 2002:5). This study compares the research findings of Downie et al. (2002:3-23) on the management of the tenant mix in shopping centers in the UK with the management of tenant mix by shopping centre property asset managers in South Africa.

The importance of the present study is that it highlights the methods that property asset managers in South Africa and the UK use to manage tenant mix in shopping centers that are similar. This will be relevant to property owners, property asset managers, property managers and investors who are active in the South African and the UK shopping centre environment, as the lifecycle of shopping centers will be extended by continuous adjustment of tenant mix two meet the changing demands of their customers.

\section{Literature review}

2.1 Tenant mix

Tenant mix is critical to the success or failure of a shopping centre (Greenspan, 1987:31; Brown, 1992:384; Kirkup \& Rafiq, 1994:29; Grenadier, 1995:357; Bruwer, 1997:170; Yim Yiu \& Xu, 2012:524). The 
main success factors of a shopping centre are quality of location; accessibility; catchment area size and quality; provision of car parking; internal layout; and environment, with tenant mix being the most critical to the success of a centre (Kirkup and Rafiq 1994:29).

Greenspan (1987:27) defines 'tenant mix' as follows: "Quite simply, a good tenant mix means having a variety of stores that work well together to enhance the performance of the entire centre as well as perform successfully as individual business." Kirkup and Rafiq (1994:29) and Brown (1992:385) cite Dawson (1983) who states that tenant mix considerations revolve around two major issues: (i) the number, nature and size of the stores in a shopping centre, and (ii) the placement of stores relative to one another and points of entry into the shopping centre. With tenant mix being critically important to shopping centers, the management and monitoring of this mix is a prerequisite (Downie et al., 2002:9).

\subsection{How to determine tenant mix}

Greenspan (1984:28) states that common sense is all that is required to determine the right tenant mix. Hernandez and Bennison (2000:357) state that the decision-making process is based on personal experience and instinct, and call the process "an art". Yiu and Xu (2012:524) refer to the tenant mix decision as "determined by gut feeling and experience".

Greenspan (1987:28), however, concluded that research is required to determine tenant mix (cf. Kirkup and Rafiq 1994:36). Bruwer (1997:170) created a cost-effective research methodology that could be used to determine the tenant mix of a shopping centre scientifically. The research model developed was on the attitude of the surrounding potential shopper population.

\subsection{Management of tenant mix}

A shopping centre can be differentiated by the unique tenant mix if offers (Kirkup \& Rafiq, 1994:29). A good tenant mix will attract shoppers from other established shopping centers and win market share for the shopping centre under management.

The management of tenant mix is crucial to the pedestrian flow within a centre. Downie et al. (2002:4) pointed out that the location of anchor and large-space users within a shopping centre draw shoppers through the centre via its access points, assisting retailers that rely on comparative and convenience shopping to survive and thrive. Wakefield and Baker (1998:515) showed that tenant mix had a strong influence on shoppers' level of excitement, which is positively linked to the levels of spending, desire to stay in a shopping centre and their intention to return in the future.

Due to the changing demographic environment surrounding the shopping centre, new store entrants and possible failures of existing stores, the tenant mix needs constant monitoring and management.

\subsection{The location of tenants in a shopping centre}

The location of tenants in a shopping centre as critical (Brown 1992:386). The placement of tenants in a shopping centre comprises certain rules: (i) place the magnet stores at opposite ends of the mall; (ii) ensure that the anchors and the entrances are sufficiently far apart; (iii) pull the shoppers past the line stores; (iv) avoid dead ends; (v) place service-orientated tenants in side malls, and close to entrances and exits; (vi) keep pet shops and dry cleaners away from food shops; (viii) keep food stores away from fashion outlets; (viii) keep an even distribution of customers within a multiple-storey mall by creating vertical access and spreading food stores.

The traffic flow within a centre is determined by the location of tenants and their requirements. Shops that pay the highest rentals are typically located within the highest traffic flow areas (Lam \& Chua, 2012:164).

\section{Research methodology}

This research compared the findings of Downie et al (2002:3-23) on the management of tenant mix in shopping centers in the UK with that in South Africa. The research design follows the quantitative structure of the research questionnaire used in Downie's approach; this allowed the findings of the two studies to be directly comparable to each other. 


\subsection{Population sample}

The criteria of the population chosen for the UK study had been that the sample be restricted to investors, asset managers, letting agents and retail asset managers, and that the minimum size of the centers that they managed had to be 25,000 square meters in size (Downie et al., 2002:11).

The present study differs from the UK study in the sample population selected in some respects: shopping centre managers and property managers were included in the study, due to their direct involvement in the management of tenant mix. Also, the sample of members was not limited to shopping centre size.

Table 1 indicates the number and percentage of respondents per position. The highest number of responses was received from property managers, who accounted $50 \%$ of the sample.

The questionnaire requested the sample members to indicate the square meters (size) of retail space and the number of shopping centers they oversaw. The size of retail centers overseen was divided into the number of shopping centers to arrive at an average. This average of the square meters was used as the square meter indicator required differentiating the retail space into smaller and larger shopping centers as per the UK study.

The shopping centre sizes ranged from 20,000 square meters to 150,000 square meters with a median of 31,250 square meters. Smaller centers had a size range of zero square meters to 31,250 square meters and larger centers had a size range of 31,250 square meters to 150,000 square meters. The divisions are based on the method used in the UK study and were used to compare the possible similarities and differences between the two shopping centre sizes. The breakdown of the square meters overseen by the respondents is represented in table two with property managers overseeing 555,000 sqm of retail space as reflected in Table 2.

\begin{tabular}{|l|c|c|}
\hline Position & Sample size in number & Percentage \\
\hline Centre manager/Leasing executive & 7 & $35 \%$ \\
\hline Property manager & 10 & $50 \%$ \\
\hline Portfolio manager & 2 & $10 \%$ \\
\hline Asset manager & 1 & $5 \%$ \\
\hline Investor/Owner & 0 & $0 \%$ \\
\hline Total & 20 & $100 \%$ \\
\hline
\end{tabular}

Table 1: Sample population size by number and percentage

\begin{tabular}{|l|c|c|}
\hline \multicolumn{1}{|c|}{ Position } & Sample size in square metres & Percentage \\
\hline Centre manager/Leasing executive & 495,000 & $40 \%$ \\
\hline Property manager & 555,000 & $45 \%$ \\
\hline Portfolio manager & 87,000 & $7 \%$ \\
\hline Asset manager & 100,000 & $8 \%$ \\
\hline Investor/Owner & 0 & $0 \%$ \\
\hline Total & $1,237,000$ & $100 \%$ \\
\hline
\end{tabular}

Table 2: Sample population by retail square meters under management

The UK research utilised a postal survey: the questionnaire designed was posted to the sample population and sample members were requested to respond by returning the questionnaire. A total of 104 questionnaires were sent, with 30 responses received, which is a response rate of 28 per cent (Downie et al., 2002:11). 
The present survey followed the same methodology and question sequence as the UK research. A structured questionnaire was sent out as an email attachment. A total of twenty responses to the questionnaire were received, which compares favourably with the thirty responses received in the UK survey. The majority of the responses were gathered from centre managers/leasing executives (seven) and property managers (ten). Two responses were received from portfolio managers and one from an asset manager.

\section{Research findings, data analysis and comparison 4.1 Evolving tenant mix}

Respondents in the South African study were asked to evaluate the importance of seven considerations for the management of the evolving tenant mix in their respective shopping centers. Each consideration was to be rated as 'not applicable', 'minor', 'important' or 'critical'. The average score of the respondents was taken into account.

Both studies consider maintaining effective anchors as the most important criteria for the management of the evolving tenant mix. This is consistent with the literature that the anchor tenant is pivotal in the creation of the image of the shopping centre and attracting shopper traffic and other tenants to the shopping centre. The most glaring difference in the survey is that in the UK study, meeting occupier demand was seen as an "important to critical" consideration. In the South Africa study meeting occupier demand was viewed as the second last consideration of importance in the management of tenant mix. Consumer demand is directly linked to the popularity of a store and the amount of traffic that is generated to the store. Downie et al. (2002: 12) was surprised that meeting unmet consumer demand was rated less than important in the UK study. They stated that shopping centre managers relied too much on retailers' demand for space and the research done by retailers for new store locations. This could potentially negatively affect the tenant mix as it would not fully reflect the demographics of the surrounding area.

The South Africa study results show that meeting unmet consumer demand is the second most important consideration in the management of tenant mix. Meeting demands from tenants is seen as the second last consideration of importance. This result could point to the fact that South African managers are more aware of their customers' requirements or that more research is done to evaluate shopper requirements. Maximising rental values and securing strong lease covenants were regarded as important in both the surveys. The South Africa study responses were sourced from the listed sector where maximisation of shareholder short-term growth is important. This is similar to the UK study. The opportunity to change tenant mix can be curtailed by the requirement to keep a tenant in occupation so as to ensure maximising rental income where a more imaginative and reflective tenant mix of the surrounding demographic could result in longer-term performance.

Of least important in both studies is that the tenant mix should reflect local stores in the surrounding areas. The indication is that managers of shopping centers compete with other shopping centers and not the retail surrounding the shopping centre.

\subsection{Location of stores}

The respondents were asked as to evaluate eight considerations which are important to the location of a store in a shopping centre as being "not applicable", "minor", "important" or "critical". Both the studies view the management of pedestrian flow through the mall as the most important factor to consider when locating a tenant within a shopping centre and are consistent with the literature.

The two studies differ as to what is regarded as the second most important factor. The UK study considered good access to catering as being the second most important factor and the reasons given are that the location of stores in UK shopping centers was mainly driven by experienced retailers who guided shopping centre managers. This was not the case in the South African study and good access to catering and separate incompatible retailers were rated sixth and seventh respectively out of eight. The influence of experienced retailers seems to have a lesser impact on the managers of South Africa centers.

The South African survey attaches greater importance on building malls for shopping centre profile and planning of mall merchandise by zoning of tenants. This is indicative of the fact that malls are seen to cater for the different images that the shoppers have of a shopping centre and that shopping centers cater for different demographic profiles that surround the shopping centre. 
Separating competing stores is seen as the least important factor in both the studies. This is consistent with the literature which found that competing stores were perceived to complement one another, and served to increase traffic flow and turnover in a specific area (Downie et al. 2002:14, Greenspan 1987:29).

\subsection{Policies for managing tenant mix}

Respondents were requested to indicate the status of their tenant mix policy. Less-developed tenant mix policies were found to be informal, outlined and unwritten and more-developed policies were found to be formal, detailed and written.

It was found that managers with a less-developed tenant mix policy for the shopping centre for which they were responsible were more open to being influenced to changing the tenant mix. This could further result in managers and investors having to defend their current tenant mix decision related to a shopping centre.

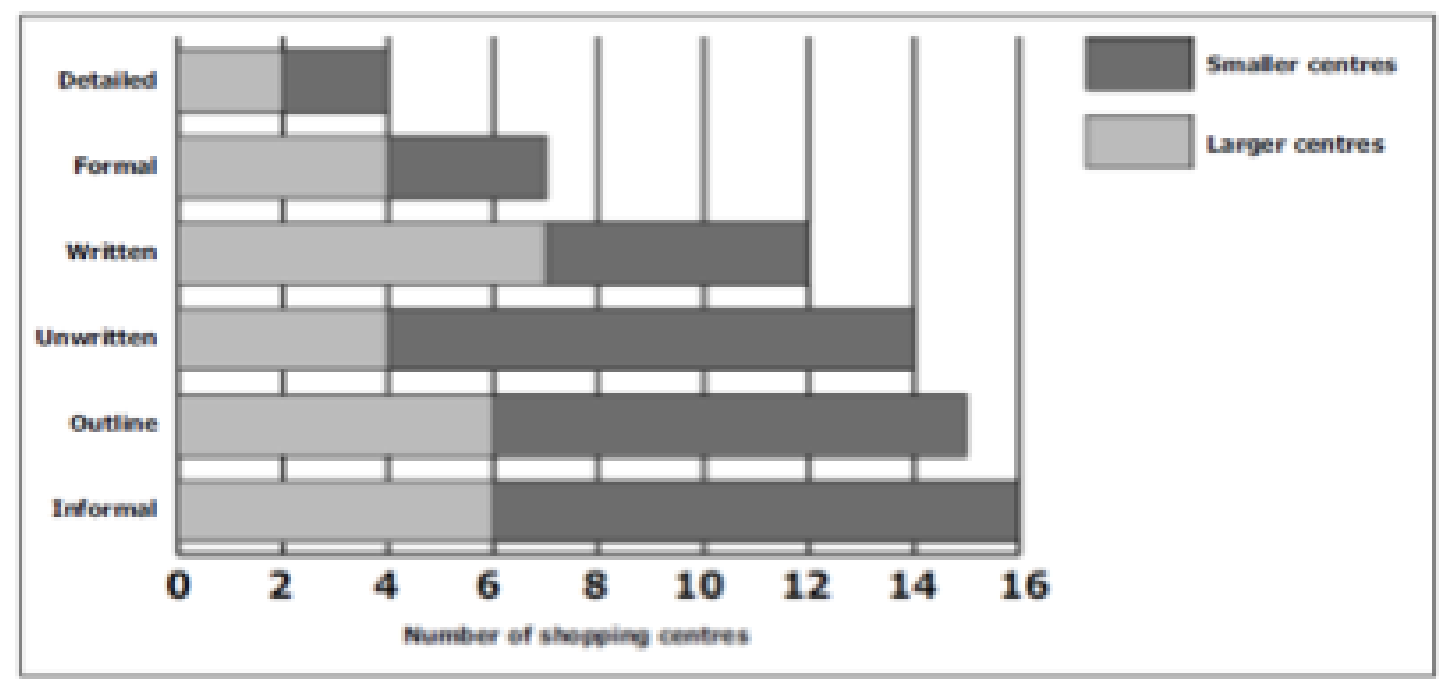

Figure 1: UK data: Status of the current tenant mix policy. Source: Downie et al. (2002:14)

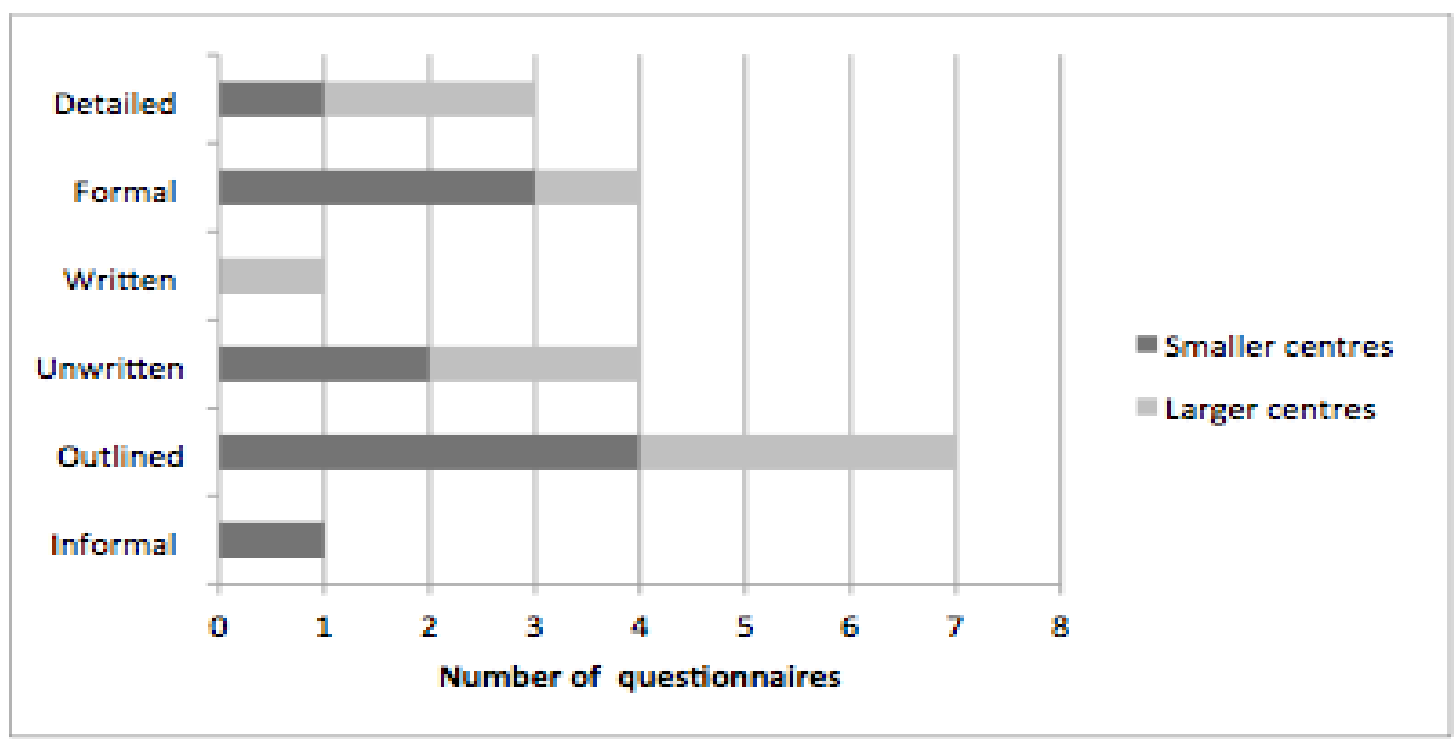

Figure 2: South African data: Status of the current tenant mix policy Source: Survey data 
The South Africa study showed a more developed tenant mix within large and smaller shopping centers than what was found in the UK study. The greatest contrast was that none of the South Africa larger centers that participated in the study had an informal tenant mix policy (figure 2), while in the UK study four shopping centers in the larger centers category had an informal tenant mix policy (figure 1). This highlights the importance of tenant mix among the regional and super regional centers in South Africa.

The more developed policy of smaller shopping centers indicates that the management of tenantmix policy is more hands-on in South Africa than in the UK. This allows the management of these shopping centers to defend their position more easily.

\subsection{Monitoring tenant mix effectiveness}

The tenant mix is crucial to the success of a shopping centre and it follows that the monitoring of the effectiveness of this aspect is crucial. Monitoring of the tenant mix falls within the responsibly of the asset manager of the shopping centre (Downie et al., 2002:9, Greenspan, 1987:27, Cloete 2002:238).

Greenspan (1987:30) recommends that the monitoring of tenant mix takes place as and when letting activity happens, and the time to act with regards to monitoring of tenant performance should start approximately one year before the evaluation of the retention of a tenant within the current tenant mix of the centre.

The respondents were requested to indicate (a) which of the following four methods, namely (i) evaluating the turnover details of the tenant, (ii) conducting retail research surveys, (iii) conducting shopper surveys and (iv) accessing turnover index data, were used monthly, quarterly, annually, infrequently or never in determining the effectiveness of tenant mix and (b) whether the tenant mix policy was reviewed annually, at irregular intervals, quarterly or with each letting activity.

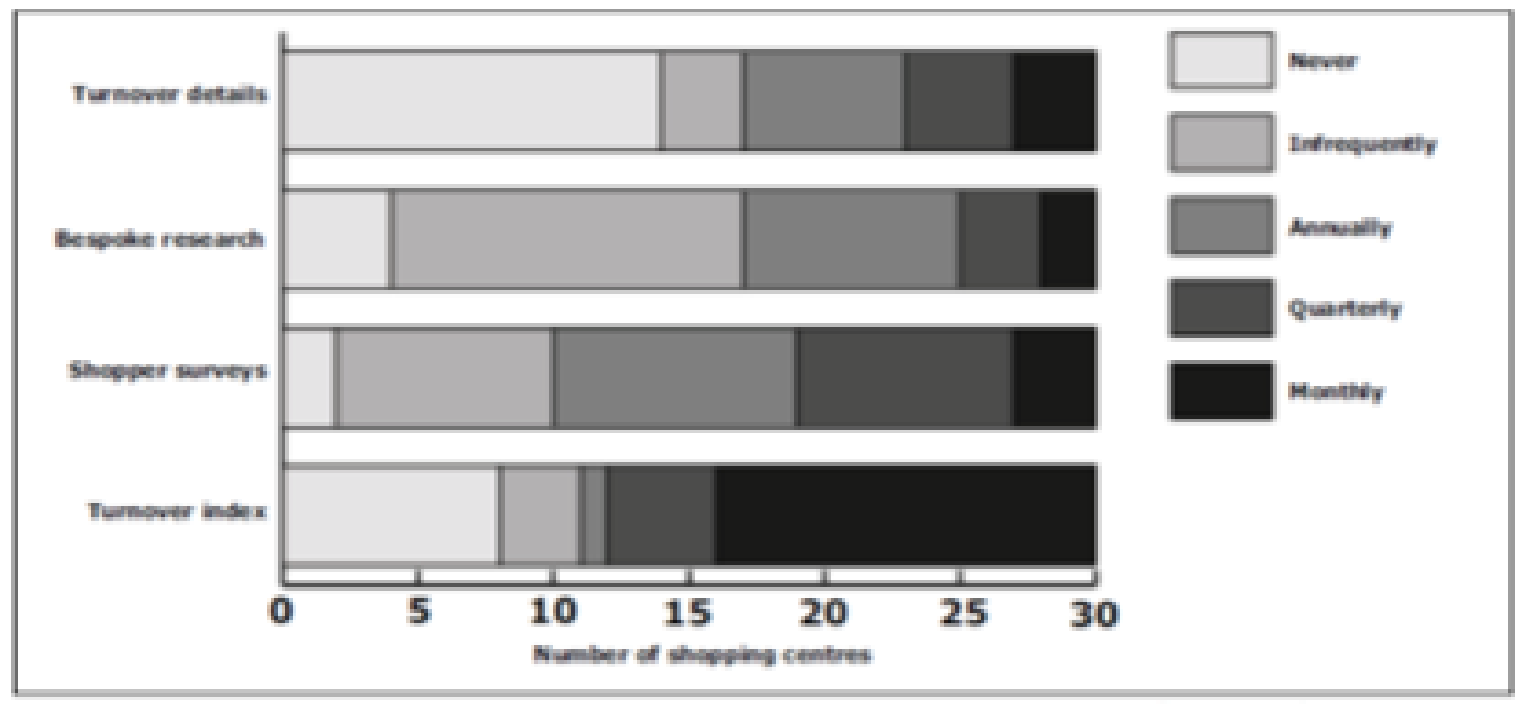

Figure 3: UK data: Methods used to monitor the effectiveness of the tenant-mix policy. Source: Downie et al. (2002:16)

Marked differences in the monitoring of tenant mix policy and methods were found to occur between the two studies.

The respondents in the South Africa study placed a high premium on gathering turnover data: $85 \%$ of the respondents indicated that they gathered turnover data monthly (figure 5) whereas less than 50 per cent of the UK respondents used turnover details to monitor effectiveness of tenant mix - this was actually the least favoured method used (figure 4). This could be indicative of the low prevalence of turnover rental leases in the UK, in conjunction with the fact that that retailers deem turnover data to be sensitive and therefore are reluctant to disclose the information. (Downie et al. 2002:15-16) The disclosure of turnover in South Africa is an indication of the success of tenants and the amount of traffic that they generate to the 
store and the shopping centre, in accordance with the literature, (Downie et al. 2002:16, Kirkup \& Rafiq 1994:31, Greenspan 1987:21)

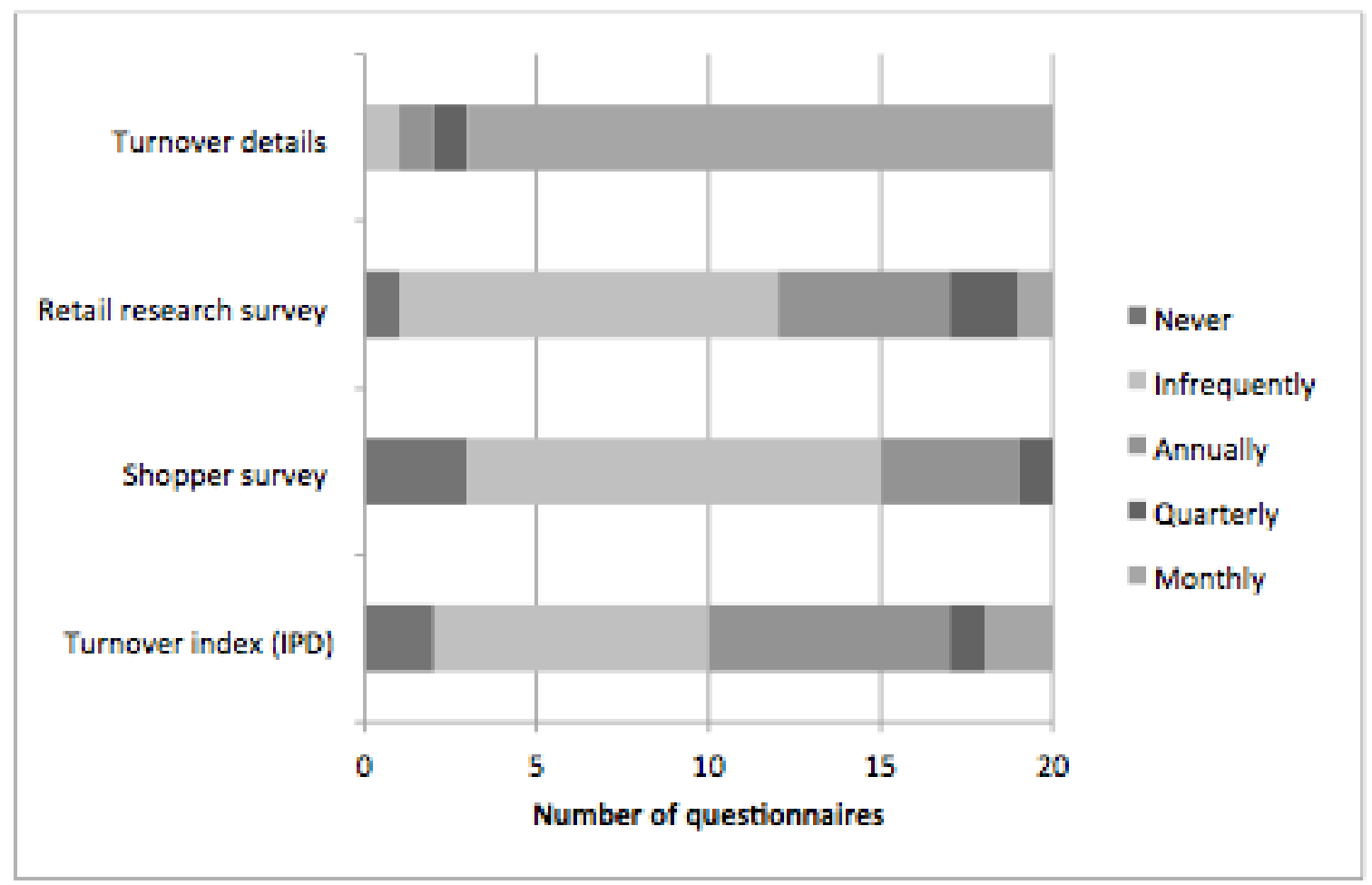

Figure 4: South African data: Methods used to monitor the effectiveness of the tenant-mix policy. Source: Survey results.

Shopper surveys is the second most used method used in the UK, whereas the South African study shows shopper surveys to be the least used method of monitoring tenant-mix effectiveness. This is possibly an indicator of cost sensitivity on the part of South African managers or that South African managers do not have the necessary skill to conduct or evaluate the results of a shopper survey study.

The above-mentioned confirms the finding in both surveys that the review of tenant-mix policy comes from other stimuli such as letting activity or tenant failure, or is reactive to events such as extensions and refurbishment of a shopping centre.

\subsection{Implementing tenant mix policy}

The UK study identified ten methods of implementing tenant-mix policies: (i) extending the shopping centre, (ii) giving concession in rentals, (iii) concluding leases of ten years or more, (iv) surrendering the leased premises without paying a premium for cancellation, (v) inserting landlord break clauses for termination of the lease, (vi) moving tenants to alternative locations, (vii) buying out tenants from their lease agreements so as to allow a change in the mix, (viii) amalgamating units to create store sizes that suit new tenant requirements, (ix) inserting clauses that limit the usage of the store and $(x)$ inserting alienation clauses to restrict transfer of rights.

The most popular method used to implement tenant mix policy in South Africa is the least popular in the UK. This could indicate the process of development and expansion of South African shopping centers in contrast with the UK.

The most popular method used in the UK is restrictions on the alienation clause, which scored close to "often" (a score of three). It is suggested in the literature that this method should always be used. The South African study found that it was utilised less frequently (a score of two to three).

The usage clause determines the range and type of goods a tenant can sell, and is fundamental to identifying the tenant placement in the tenant mix. Restrictions placed on the usage of the premises were 
seen as the second most often used method to influence tenant mix in both the UK and South African studies.

The least popular method to implement tenant mix in the South Africa study was to buy tenants out of their lease agreements. In the follow-up interviews in the UK study the interviewed respondents indicated that this was the most proactive way of changing the tenant-mix policy, namely to buy out tenants and thereby allowing new entrants into the shopping centre and it also allowed the manager to change unit sizes to accommodate the retailer's unit size needs.

\subsection{Tenant mix obsolescence}

The final two questions of the study were focused on the obsolescence of the current tenant mix: whether the tenant mix of the shopping centre had kept up with modern retail trends and what factors hindered updating the tenant mix policy if it had not kept up with modern retail trends. The shopping centers had been split into larger and smaller centers to determine if there was any significant difference of opinion between the two centre sizes regarding the two questions. To evaluate the extent that the shopping centers had been able to keep up with modern retail trends, the respondents were asked to choose between the following descriptions, "poorly", "partially", "fairly", "well" and "completely".

The respondents were also requested to identify which of the following factors hindered the updating of the tenant mix and if they were critical, important, minor or not applicable: lack of proactive management, lack of investment, lack of retailer demand, long lease, lack of vacant units and inappropriate unit sizes. The two surveys follow the same pattern, with the majority of managers of larger shopping centers feeling that their centers kept up to date with modern retail trends well, and the smaller shopping centers managers only partially kept up to date with modern retail trends.

The results of the factors that hinder the updating of tenant mix in both surveys were similar, indicating that similar concerns are prevalent in the UK and South Africa. Lack of vacant units and inappropriate unit sizes were seen to be the "most important to critical" factor in the UK and South Africa, with inappropriate box sizes in the UK survey and the lack of vacant units in the South African survey being the most important factors respectively. Larger centers regard the hindrance of a long lease to updating tenant mix as being more important than do the smaller centers in both the studies. This indicates that larger space users are more prevalent in larger centers and request longer leases so as to have an opportunity to recover their initial capex cost.

Both surveys scored "lack of proactive management" and "lack of investment" as being either a minor hindrance or not applicable to updating the tenant mix in shopping centers. This finding indicates that proactive management prevails among the shopping centre managers in the UK as well as in South Africa and that if investment opportunities required the updating of tenant mix, managers were allocated the necessary investment funds to update the tenant mix.

\section{Summary, conclusions and further research \\ 5.1. Introduction}

The present study has established that while the management techniques employed by managers of shopping centers in the UK and South African were similar and also conformed to extant literature on the subject, techniques used for some of the objectives were the complete opposite of each other in a few cases. These findings could possibly be ascribed to the differences in the countries' economic, cultural and legislative environments.

\subsection{Summary}

5.2.1 First objective: To determine what is required to maintain an effective tenant mix in shopping centers.

The respondents in both studies regarded maintaining effective anchors as being the most important consideration for shopping centers and for positioning the shopping centre image in the minds of shoppers. The anchor tenant was also instrumental in positioning the shopping centre in relation to its competitors, and attracting complementary tenants and shopper traffic to the shopping centre.

Customers' unmet demand for retail stores in shopping centers were rated highly by South African managers, while UK managers viewed unmet demand by customers as less than important. The explanation in the UK study was that demand was driven by specialist retail operators who were aware of their store requirements and that the UK managers were guided by these requirements. 
The means used to implement tenant-mix policy showed the following similarities between the two studies: managers inserted usage clauses in lease agreements to control the allowed usage, and also inserted alienation clause restrictions in lease agreements, allowing control of the tenant mix. The following differences were found: in South Africa the extension of a shopping centre to maintain an effective tenant mix was used often and buying out tenants was seldom used. In the UK extending the centre was the least most popular method used and the method of buying out tenants was sometimes used too often. The differences highlighted the level of maturity of the two countries' shopping centre environments: rather than waiting for a vacancy to place a tenant in a UK shopping centre, buying tenants out of their lease was a consideration.

The two studies showed similar responses in respect of factors that hindered the updating of tenant mix in shopping centers. Managers in both studies considered the ability of shopping centre managers to access vacant units and unit sizes that fitted the requirements of retailers to be "critical to important ". This would give managers the ability to meet retailers' demand for vacant units and appropriate unit sizes, and therefore also meet the requirements of shoppers for the placement of retailers to meet the shoppers' unmet demand in the shopping centre.

\subsubsection{Second objective: To determine the factors that influences the location of tenants in a shopping centre.}

The management of pedestrian flow was seen by both studies as the most important factor that influenced the location of a tenant in a shopping centre and the literature confirms this finding. Consistent with the consideration of an effective tenant mix the UK managers regarded factors that related to retailer demand as important to critical. Factors such as good access to catering and separation of incompatible retailers within the shopping centre environment were viewed as being important; again, highlighting the influence of retailers' requirements and choices of specific location. In contrast, the South Africa managers regarded the building of malls for different shopper profiles and the grouping of comparison retailers as being important considerations.

\subsubsection{Third objective: To determine to what extent tenant-mix policies are documented by property asset managers.}

The tenant-mix policy in both the studies tended to be informal for smaller centers and more formal for larger centers. The formal approach adopted by larger centers indicated the importance of a more formal tenant-mix policy within a larger centre environment which, due to the larger scale and number of tenants, would guide and direct the execution of policy.

The frequency of tenant-mix policy reviews followed the same pattern as the status of the policy. Shopping centers that had a more formal tenant mix policy being reviewed at fixed intervals (either quarterly or annually) and shopping centers with an informal policy reviewed their policies on a more ad hoc basis. The even split of shopping centers along the median of square meters could influence this result, as smaller shopping centers were typically found to have a more informal status regarding tenant mix and therefore a more informal policy.

Larger shopping centers with their more formal tenant mix policy guidelines and with more reviews at set periods indicated that they were more responsive to modern retail trends. A consequence of an informal policy that was only reviewed on an ad hoc basis was a tenant mix that only partially or fairly reflected the changes in modern trends.

\subsubsection{Fourth objective: To determine the main methods used to monitor tenant-mix policies.}

The respondents were questioned on the frequency with which methods were used to monitor tenant mix.

The monitoring of turnover showed the highest frequency of use in both studies. In the South African study, the monitoring of tenants' retail figures was done on a monthly basis. Owing to restrictions on the disclosure of turnover figures, managers in the UK utilised the turnover index as a monitoring tool of the tenant mix policy.

The respondents in both studies found utilising shopper surveys and retail research surveys prohibitive from a cost and skills analysis requirement point of view.

\subsection{Conclusion}

This study established that, generally, the same techniques were used by respondents in South Africa as had been found in the UK, and that a similar level of importance and frequency of use were attached 
to each technique. The monitoring of turnover by evaluating monthly turnover figures or accessing a turnover index on a monthly or yearly basis was found to be the most important tool to monitor, and thereby manage, the tenant mix.

The anchor tenant was seen as the most crucial element of the tenant mix of a shopping centre, because it attracts complementary large- and small-space user stores to the shopping centre. It plays a large role in determining the image of the shopping centre in the mind of the shopper. Determining the requirements of an effective tenant-mix policy in the UK was guided by retail store specialists, who guided shopping centre managers in the placement of stores, merchandising of the tenant mix and the clustering of comparative stores. Managers in South Africa utilised expansion of shopping centres and sourcing tenants to meet shopper demand as a more frequently used method to maintain an effective tenant mix, indicating a more shopper-centric approach to tenant mix.

In both studies the lack of vacant units and inappropriate unit sizes for retailer requirements were seen as the biggest hindrances to updating the tenant mix. Ironically, failure of a tenant (which could be seen as a failure of the effectiveness of the tenant mix) allowed the opportunity for a shopping centre manager to update the tenant mix.

Attracting shoppers to shopping centres and managing pedestrian flow between stores was seen as the most important factor in locating tenants within a shopping centre in both studies. The specialist store retailers in the UK had a greater influence on the location of tenants than was the case in South Africa shopping centres. This conforms to the influence that specialist retail stores have on the effectiveness of tenant mix in the UK. In contrast, managers in South African centres regarded the building of shopping centres as reflecting the surrounding demographics of the area and the clustering of compatible retailers as being more important than adhering to retailer demand.

A more formal tenant-mix policy that is reviewed at fixed intervals resulted in a tenant mix that better reflected modern retail trends. In both studies it was found that the larger shopping centres had more formal tenant-mix policies in place than the smaller shopping centres, with the respondents of larger shopping centres being more comfortable that their shopping-centred tenant mix reflected modern retail trends.

The respondents in both the surveys acknowledged the importance of turnover monitoring by frequently monitoring either monthly turnover amounts (in the case of South African centres) or, if due to restrictions on gaining access to turnovers, the use of turnover indexes (in the case of the UK centres). Alternative methods of monitoring effectiveness of tenant mix through conducting of shopper surveys and through retail research were deemed to be restrictive from a cost and skills perspective in both studies.

In conclusion, it was found that respondents in both the surveys managed tenant mix in accordance with the findings in the literature.

\subsection{Further research}

The management of tenant mix is of critical importance to the success or failure of shopping centers. During the research, questions and statements that were pertinent to tenant mix were raised that did not form part of the study and further research is recommended in answering the following questions and statements:

i.Who is responsible for determining the tenant mix policy of a shopping centre?

ii.How can centers update their tenant mix without relying on vacancies to occur?

iii.The development of a template for a formal tenant mix policy.

In view of the expansion of South African shopping centre ownership in Africa, Eastern and Southern Europe, it will also be interesting to ascertain whether the same similarities and differences as had been found in UK and South Africa also prevail in other countries with different cultures.

\section{References}

Brown, S. (1992). Tenant mix, tenant placement and shopper behaviour in a planned shopping centre. Service Industries Journal, 12(3), 384-403.

Cloete, C. E. (ed.) (2002). Management of commercial and industrial properties. Sandton: S A Property Education Trust.

Bruwer, J. (1997). Solving the ideal tenant mix puzzle for a proposed shopping centre: a practical research methodology. Property Management, 15(3), 160-172. 
Downie, M. L., Fisher, P., \& Cheryl, W. (2002). Managing tenant mix in shopping centers in the UK. Research Papers Northumbria University. Newcastle upon Tyne: Northumbria University, 4(14).

Forgey, F. A., Goebel, P. R., \& Nixon, B. (1995). Addressing tenant site selection to maintain shopping center success. Economic Development Review, 13(2), 56.-59.

Greenspan, J. (1987). Solving the tenant mix puzzle in your shopping centre. Journal of Property Management, 53(4), 27-31.

Grenadier, S. R. (1995). Flexibility and tenant mix in real estate projects. Journal of Urban Economics, 38(3), 357-378.

Hernandez, T., \& Bennison, D. (2000). The art and science of retail location decisions. International Journal of Retail \& Distribution Management, 28(8), 357-367.

Kirkup, M. \& Rafiq, M. (1994). Managing tenant mix in new shopping centers. International Journal of Retail and Distribution Management, 22(6), 29-37.

Lam, B. Y., \& Chau, K. W. (2012). Explaining the variations in the pedestrian flow values of shopping centers. Facilities, 30(3/4), 164-176.

Wakefield, K. L. \& Baker, J. (1998). Excitement at the mall. Journal of retailing, 74(4), 515.-539.

Yim Yiu, C. and Xu, S.Y., (2012). A tenant-mix model for shopping malls. European Journal of Marketing, $46(3 / 4), 524-541$. 